\title{
A EFETIVIDADE DA DIGNIDADE HUMANA NAS RELAÇÕES INTERPRIVADAS PELA VIVÊNCIA DA SOLIDARIEDADE
}

\author{
SCHROEDER, H. C.1; REIS, J. R. ${ }^{2}$
}

PALAVRAS CHAVE: Constitucionalização do Direito Privado. Constituição Federal. Dignidade Humana. Princípio da Solidariedade. Relações Interprivadas.

\begin{abstract}
RESUMO
0 presente artigo aborda o novo contexto sócio-jurídico-político e constitucional estabelecido no cenário nacional pela Constituição Federal de 1988, o qual permite verificar pontos de intersecção entre direito público e direito privado. Ainda, os princípios constitucionais, em razão da força normativa que a Constituição obteve, passam a ter efeitos sobre todo o ordenamento jurídico. Sendo assim, o princípio constitucional da solidariedade encaixa-se nesse cenário, pois passa a ser reconhecido e observado tanto no âmbito das relações públicas como nas relações privadas, com o propósito de concretizar os direitos fundamentais realizadores da dignidade da pessoa humana. Nesse sentido, o objetivo do trabalho é verificar a efetividade da dignidade humana nas relações interpessoais pela vivência da solidariedade. Como resultado, é possível verificar a mudança da dinâmica das relações interprivadas, a partir do entendimento da importância do princípio da solidariedade e da sua vivência, garantindo o respeito à dignidade, assim como o bem estar comum, evitando a litigiosidade nestas relações. 0 método de abordagem utilizado foi o dedutivo e a técnica de pesquisa empregada foi à documentação indireta, através de referências doutrinárias publicadas em documentos científicos.
\end{abstract}

\section{THE EFFECTIVENESS OF HUMAN DIGNITY IN THE INTERPERSONAL RELATIONSHIPS BY THE SOLIDARITY EXPERIENCE}

KEYWORDS: Constitutionalisation of Private Law. Federal Constitution. Human Dignity. Principle of Solidarity. Interpersonal relationships.

\begin{abstract}
This article approaches the new socio-juridical-political and constitutional context established in the national scenario by the Federal Constitution of 1988, which allows to verify points of intersection between public law and private law. Moreover, the constitutional principles, because of the normative force that the Constitution obtained, produce effects on the entire legal system. Therefore, the constitutional principle of solidarity fits into this scenario, since it is recognized and observed in public relations and also in private relations, focused in realizing the fundamental rights that make the dignity of the human being. In this regard, the objective of this work is to verify if the effectiveness of human dignity in interpersonal relationships through the solidarity experience. As a result, it is possible to verify the change in the dynamics of interpersonal relations, starting from the understanding of the importance of the principle of solidarity and its experience, guaranteeing the respect to the dignity, as well as the common well-being, avoiding the litigiousness in these relations. The approach method used was the deductive method and the research technique employed was indirect documentation through doctrinal references published in scientific documents.
\end{abstract}

\footnotetext{
${ }^{1}$ Acadêmica do curso de Direito na Universidade de Santa Cruz do Sul.

2 Docente do Departamento de Direito na Universidade de Santa Cruz do Sul.
} 


\section{INTRODUÇÃo}

Contemporaneamente, é possível constatar uma inserção de preceitos e valores de direito público, especialmente constitucionais, no âmbito do direito privado, assim como a inserção de regras e institutos próprios do direito privado no âmbito do direito público. Neste sentido, o direito privado e o direito público não são institutos totalmente apartados, característica que predominava no Estado Liberal. Assim, diante do novo contexto sóciojurídico-político e constitucional, estabelecido no cenário nacional pela Constituição Federal de 1988, que se pode denominar de Estado Social Democrático, foi permitido verificar pontos de intersecção entre direito público e direito privado.

Além do mais, os direitos fundamentais e, especialmente os princípios constitucionais, em razão da força normativa que a Constituição obteve, passam a ter efeitos sobre todo o ordenamento jurídico. Sendo assim, o princípio constitucional da solidariedade, que está consagrado no artigo $3^{\circ}$, inciso I, da Constituição Federal de 1988, encaixa-se nesse cenário, pois passa a ser reconhecido e observado tanto no âmbito das relações públicas como nas relações privadas, com o propósito de concretizar os direitos fundamentais realizadores da dignidade da pessoa humana e, ao mesmo tempo, repelindo a lógica essencialmente individual e patrimonialista. Tem-se que a solidariedade é uma questão de responsabilidade social para com o estabelecimento de uma ordem justa, que tem como preocupação o direito/dever de cada um para com todos.

Em face dessas premissas, a pesquisa procura responder ao problema: de que forma o princípio constitucional da solidariedade dá efetividade à dignidade da pessoa humana nas relações interprivadas? Neste sentido, o objetivo é verificar a efetividade da dignidade humana nas relações interpessoais pela vivência da solidariedade.

Dito isso, arquiteta-se a estrutura da pesquisa em três pontos. Inicia-se a análise a partir do fenômeno da constitucionalização do direito privado no constitucionalismo contemporâneo. No segundo momento, busca-se mencionar o contexto da dignidade da pessoa humana no cenário da Constituição Federal de 1988, além de trazer uma noção do significado da dignidade humana, para, assim, fazer alguns pontos de contato com os direitos fundamentais. Logo, passa-se para o terceiro tópico do artigo, o qual menciona acerca do princípio constitucional da solidariedade, especialmente sua aplicação nas relações interprivadas, destacando o contexto histórico do seu surgimento, trazendo suas conceituações e particularidades.

Utilizar-se-á, para tanto, como método de abordagem o dedutivo e a técnica de pesquisa volta-se ao estudo da documentação indireta, através de referências doutrinárias publicadas em documentos científicos, como obras doutrinárias, artigos, periódicos e revistas.

\section{A CONSTITUCIONALIZAÇÃO DO DIREITO PRIVADO NO CONSTITUCIONALISMO CONTEMPORÂNEO}

De forma a iniciar o assunto e para melhor compreensão acerca da mudança de paradigma no direito civil, faz-se necessário realizar alguns apontamentos acerca da superação da grande divisão dicotômica entre público e privado, para, assim, versar sobre a constitucionalização do direito privado no constitucionalismo contemporâneo, seu contexto histórico e seus desdobramentos no ordenamento jurídico. 
Assim sendo, conforme Neto (2010, p. 38), o fenômeno da constitucionalização do direito privado retrata a superação da visão que separava o direito público e o direito privado em dois mundos opostos no universo jurídico, interpretação que gerou a grande dicotomia entre os direitos. Utiliza-se o termo dicotomia quando encontramos uma distinção em que, a partir dela, pode-se dividir um universo em duas esferas, conjuntamente exaustivas e reciprocamente exclusivas.

A diferenciação entre o que é considerado direito público e classificado como direito privado geralmente é feita pelos juristas, utilizando-se para tanto critérios distintos. Em síntese, as relações de direito privado seriam definidas pela igualdade dos sujeitos, havendo relações de coordenação. Já as relações de direito público seriam aquelas qualificadas pela desigualdade dos sujeitos, corresponderiam, por consequência, as relações de subordinação. Desta forma, o direito privado seria assim classificado pela proteção que proporciona aos interesses privados e o direito público, pela segurança oferecida aos interesses coletivos (BOBBIO apud NETO, 2010, p. 3839).

Porém, contemporaneamente, é possível verificar uma inserção de preceitos e valores de direito público, especialmente constitucionais, no âmbito do direito privado, bem como a inserção de regras e institutos próprios do direito privado no âmbito do direito público. Neste sentido, o direito privado e o direito público não são institutos totalmente apartados, característica que predominava no Estado Liberal.

Isto posto, a respeito de uma abordagem histórica do surgimento da constitucionalização do direito privado, tem-se que as codificações de modo geral, mas, especialmente os códigos civis que acompanharam o chamado Estado Liberal, eram essencialmente individuais e patrimonialistas, características predominantes do liberalismo. Por conseguinte, o código civil brasileiro de 1916 possuía como modelo o cidadão proprietário que tinha patrimônio, ou seja, a norma civil tutelava o homem que dispunha capital e propriedade, afastando, logo, uma grande parcela de pessoas de sua tutela (REIS, 2009).

Como resultado, para aqueles que vivenciaram o Estado Liberal, a liberdade se caracterizava como o direito de usar, gozar e dispor de sua propriedade sem a intervenção do Estado, ressalvando apenas aqueles mínimos ditados pela ordem pública e pelos bons costumes (REIS, 2009). Ainda acerca deste contexto do liberalismo e suas consequências no direito civil, tem-se que:

0 direito privado, especialmente o direito civil, atravessou os tempos sob o signo da livre-iniciativa e da autonomia da vontade. As doutrinas individualistas e voluntaristas, consagradas pelo Código Napoleônico (1804) e incorporadas pelas codificações do século XIX, repercutiram sobre o Código Civil brasileiro de 1916. A liberdade de contratar e o direito de propriedade fundiam-se para formar o centro de gravidade do sistema privado. Ao longo do século XX, todavia, esse quadro se alterou. A progressiva superação do liberalismo puro pelo intervencionismo estatal trouxe para o domínio do direito privado diversos princípios limitadores da liberdade individual e do primado da vontade, denominados princípios de ordem pública (BARROSO, 2011, p. 80-81).

Contudo, a história evidenciou que a codificação baseada no liberalismo, sem interferências do Estado, apresentou como resultado a exploração daquele que era considerado mais fraco pelo mais forte. Neste sentido, a sociedade classificada como "pós-moderna", não mais concordava com o modelo da igualdade formal e da autonomia da vontade pregada pelo ideal liberal, pleiteando que o Estado tomasse atitudes, prestando uma proteção mais efetiva. 0 Estado passou, portanto, a intervir na organização da vida econômica das pessoas com o propósito de estabelecer um equilíbrio entre os particulares, objetivando diminuir as desigualdades materiais existentes em busca de uma justiça social (REIS, 2009).

Sendo assim, ocorre também uma acentuação do processo denominado de publicização do direito privado, dando espaço a um novo desenvolvimento dogmático: a constitucionalização do direito civil. Afirmava-se 
inicialmente que o código civil era a Constituição do direito privado e efetivamente existia uma divisão, como já explanado, na qual de um lado havia o direito privado, protagonizado pelos contratantes e os proprietários, possuindo como matéria principal a autonomia da vontade. Já de outro lado, havia o direito público, em que os atores principais eram o Estado e o cidadão e a questão central, por sua vez, era o exercício do poder e os limites decorrentes dos direitos individuais (BARROSO, 2011, p. 81-82).

Porém, no decorrer do tempo, com o surgimento das novas demandas da sociedade tecnológica e da crescente consciência social de todos no tocante aos direitos fundamentais, proporcionou-se a superposição entre o público e o privado. Assim sendo, na direção desse movimento, tem-se a despatrimonialização do direito civil (BARROSO, 2011, p. 82).

É possível constatar que a Constituição já era vista como lei fundamental, contudo era considerada apenas como um estatuto que regia a vida política do Estado, não se vinculando nas relações interprivadas. Entretanto, a Carta Magna passou a expressar supremacia também no campo normativo, em todo o seu âmbito. Como consequência, o ponto central do ordenamento, que era o código civil, passou a ser a Constituição Federal, e esta unifica em torno de si todo o complexo de normas que constitui o ordenamento jurídico, manifestando uma ordem material de valores (FINGER, 2000, p. 93-94). Sendo assim, tem-se que:

\begin{abstract}
No quarto final do século, o Código Civil perde definitivamente o seu papel central no âmbito do próprio setor privado, cedendo passo para a crescente influência da Constituição. No caso brasileiro específico, a Carta de 1988 contém normas acerca da família, da criança e do adolescente, da proteção do consumidor, da função social da propriedade. Além disso, os princípios constitucionais passam a condicionar a própria leitura e interpretação dos institutos de direito privado. A dignidade da pessoa humana assume sua dimensão transcendental e normativa. A Constituição já não é apenas o documento maior do direito público, mas o centro de todo o sistema jurídico, irradiando seus valores e conferindo-lhe unidade (BARROSO, 2011, p. 82).
\end{abstract}

Como resultado da soberania da Constituição Federal, compreende-se que esta requer que todos os atos praticados sob a sua égide, a ela se coadunem, podendo sofrer pena de inexistência, nulidade, anulabilidade ou ineficácia caso os atos a atentarem, de acordo com o princípio da constitucionalidade. Nesta perspectiva, todo o direito infraconstitucional é considerado direito constitucionalizado, sendo que não se pode cogitar um direito civil autônomo em relação ao direito constitucional (FINGER, 2000, p. 94).

Em consequência da constitucionalização do direito, verifica-se que o código civil brasileiro, o qual anteriormente possuía seu ideal extremamente individual e patrimonialista, voltado substancialmente para o homem que dispunha patrimônio, vem sufragado pelo paradigma de conteúdo social, estabelecido pelos princípios constitucionais da Constituição Federal de 1988, primando de forma nunca vista no âmbito privado, a dignidade da pessoa humana (REIS, 2009).

Essa conjuntura ocasiona, em suma, como já mencionado, a superação da rígida dicotomia entre o direito público e o direito privado. Tal cenário se torna mais evidente perante a tendência de descodificação do direito civil, através da manifestação de diversos microssistemas no ordenamento jurídico, tais como o Código de Defesa do Consumidor, a Lei de Locações, a Lei de Direito Autoral, o Estatuto da Criança e do Adolescente, o Estatuto do Idoso, a Lei de Alimentos, e o Estatuto da Pessoa com Deficiência. Sendo assim, todos estes referidos microssistemas, entre outros, encontram o seu fundamento na Carta Magna de 1988, norma que possui validade em todo âmbito jurídico, passando o direito civil por um processo denominado de despatrimonialização, bem como pelo fenômeno da constitucionalização do direito privado (LENZA, 2012, p. 55).

Em síntese, o processo de constitucionalização do direito privado, que possui como característica a exaltação do ser humano, trazendo ao seio do direito privado regras constitucionais, está diretamente ligado com 
os fenômenos da repersonalização do direito privado ou despatrimonialização do direito civil, visto que coloca o indivíduo no topo da proteção do direito privado. Sendo assim, analisar-se-á no tópico que segue a dignidade da pessoa humana, especialmente na Carta Magna e os direitos fundamentais.

\section{A DIGNIDADE DA PESSOA HUMANA NA CONSTITUIÇÃO FEDERAL DE 1988 E OS DIREITOS FUNDAMENTAIS}

De forma a iniciar o tema, é essencial mencionar o contexto da dignidade da pessoa humana no cenário da Constituição Federal de 1988, além de trazer uma noção do significado da dignidade humana, para, assim, fazer alguns pontos de contato com os direitos fundamentais.

A Constituição Federal brasileira em vigor, a qual se manifesta como uma reação ao período anterior, que era autoritário, foi à primeira na trajetória do constitucionalismo pátrio a possuir um título próprio reservado aos princípios constitucionais. A Carta Magna seguiu semelhante percurso que foi trilhado pela Lei Fundamental da Alemanha e pelas Constituições de Portugal e da Espanha. Neste contexto, sem precedentes na história nacional, ocorreu o reconhecimento da dignidade da pessoa humana no âmbito do direito constitucional positivo (SARLET, 2001, p. 61-62).

Sendo assim, em 1988, o Brasil estabeleceu na sua Constituição Federal, no artigo $1^{\circ}$, inciso III, que a República Federativa do Brasil constitui-se em Estado Democrático de Direito e tem como fundamento a dignidade da pessoa humana, ao lado da soberania, cidadania, valores sociais do trabalho e da livre iniciativa e do pluralismo político (BRASIL, 1988).

Na Constituição Federal brasileira de 1988, a dignidade da pessoa humana não está prevista somente no artigo $1^{\circ}$, inciso III, mas ainda em outros três trechos. 0 primeiro deles é o artigo 226, que trata da família, relacionando a dignidade humana ao planejamento familiar. Sendo assim, de acordo com o dispositivo, em seu $\S 7^{\circ}$, "fundado nos princípios da dignidade da pessoa humana e da paternidade responsável, o planejamento familiar é livre decisão do casal, competindo ao Estado propiciar recursos educacionais e científicos para o exercício desse direito, vedada qualquer forma coercitiva por parte de instituições oficiais ou privadas" (BRASIL, 1988).

Encontra-se igualmente referência à dignidade da pessoa humana nos artigos que versam sobre crianças, adolescentes e a respeito da proteção aos idosos. 0 artigo 227 da Constituição Federal brasileira dispõe que é obrigação conjunta da família, da sociedade em geral e do Estado garantir à criança, ao adolescente e ao jovem, “com absoluta prioridade, o direito à vida, à saúde, à alimentação, à educação, ao lazer, à profissionalização, à cultura, à dignidade, ao respeito, à liberdade e à convivência familiar e comunitária, além de colocá-los a salvo de toda forma de negligência, discriminação, exploração, violência, crueldade e opressão" (BRASIL, 1988).

Tem-se também o artigo 230, o qual indica que "a família, a sociedade e o Estado têm o dever de amparar as pessoas idosas, assegurando sua participação na comunidade, defendendo sua dignidade e bem-estar e garantindo-Ihes o direito à vida" (BRASIL, 1988).

Logo, estando positivada na Constituição como um dos fundamentos da República Federativa do Brasil, pode-se verificar que a dignidade da pessoa humana traduz-se no valor absoluto e subordinante, e, ainda, é vista como o mandamento nuclear da Constituição Federal de 1988 (RICHTER; TABARELLI, 2008, p. 79).

A respeito do conceito da dignidade da pessoa humana, Sarlet (2001, p. 38-39) menciona a dificuldade de 
defini-la de forma clara e concreta do que efetivamente seja:

Tal dificuldade, consoante exaustiva e corretamente destacado na doutrina, decorre certamente (ao menos também) da circunstância de que se cuida de conceito de contornos vagos e imprecisos, caracterizado por sua "ambiguidade e porosidade", assim como por sua natureza necessariamente polissêmica, muito embora tais atributos não possam ser exclusivamente atribuídos à dignidade da pessoa. Uma das principais dificuldades, todavia - e aqui recolhemos a lição de Michael Sachs - reside no fato de que no caso da dignidade da pessoa, diversamente do que ocorre com as demais normas jusfundamentais, não se cuida de aspectos mais ou menos específicos da existência humana (integridade física, intimidade, vida, propriedade, etc.), mas, sim, de uma qualidade tida como inerente a todo e qualquer ser humano, de tal sorte que a dignidade [...] passou a ser habitualmente definida como constituindo o valor próprio que identifica o ser humano como tal, definição esta que, todavia, acaba por não contribuir muito para uma compreensão satisfatória do que efetivamente é o âmbito de proteção da dignidade, na sua condição jurídico-normativa.

Ainda, tem-se que a razão de o termo possuir tantos conceitos decorre das diferenças que existem de uma sociedade para outra e de um espaço para outro, dado que são produzidos, notadamente, por influências religiosas, filosóficas e também morais. Assim sendo, dentro de uma determinada sociedade e de um estipulado espaço, o termo dignidade irá possuir um significado, que poderá tornar-se, de acordo com Awad (2006, p. 115), “mais amplo ou menos restrito, de pessoa para pessoa, dentro desse mesmo corpo social. Considera-se que o objeto de proteção estende-se a qualquer pessoa, independentemente da idade, sexo, origem, cor, condição social, capacidade de entendimento e autodeterminação ou status jurídico". Mas, conclui-se que apesar de a palavra "dignidade" possuir vários conceitos, estes possuem a mesma essência.

Além disso, é possível constatar uma relação entre a autonomia da vontade e a dignidade da pessoa humana. Sendo assim, tem-se que, de acordo com Sarlet (2011, p. 40):

\begin{abstract}
Construindo sua concepção a partir da natureza racional do ser humano, Kant assinala que a autonomia da vontade, entendida como a faculdade de determinar a si mesmo e agir em conformidade com a representação de certas leis, é um atributo apenas encontrado nos seres racionais, constituindo-se no fundamento da dignidade da natureza humana. Em síntese [...], é possível acompanhar Thadeu Weber quando refere que autonomia e dignidade estão, notadamente no pensamento de Kant, intrinsecamente relacionados e mutuamente imbricados, visto que a dignidade pode ser considerada como o próprio limite do exercício do direito de autonomia, ao passo que este não pode ser exercido sem o mínimo de competência ética.
\end{abstract}

Há ainda uma íntima semelhança entre o princípio da dignidade da pessoa humana e o direito natural, pois se o direito natural é caracterizado como aquele que nasce com o homem, a dignidade humana, assim, faz parte dele. E ao nascerem, todos os homens são iguais em dignidade, o que irá diferenciá-los posteriormente, é o contexto sociocultural e econômico em que estão colocados (AWAD, 2006, p. 114).

De qualquer modo, mesmo apresentando a dificuldade mencionada referente à sua conceituação, não restam dúvidas de que a dignidade da pessoa humana é real e de substancial importância, estando positivada de forma expressa na Constituição Federal de 1988, ela serve de base para todas as ações do Estado e dos cidadãos e se irradia para todo o ordenamento jurídico.

Após verificar a presença expressa da dignidade da pessoa humana na Constituição Federal e de buscar conceitua-la, parte-se para alguns pontos de contato desta com os direitos fundamentais. De forma a iniciar, verifica-se que, conforme Sarlet (2011), os direitos fundamentais consistem em explicitações da dignidade da pessoa, ou seja, em cada direito fundamental há um teor da dignidade humana. Ainda, a dignidade da pessoa humana reclama e presume o reconhecimento e defesa dos direitos fundamentais de todas as dimensões ou gerações.

Sendo assim, de forma a estabelecer tais classificações em dimensões como marcos da evolução dos direitos fundamentais e das lutas em busca da obtenção das liberdades que gradualmente se opunham às opressões suportadas pelo homem, tem-se que os direitos de primeira dimensão estão relacionados às liberdades 
públicas e à imposição de limites à atuação do Estado, possuindo por titular o indivíduo livre e autônomo no tocante ao exercício de direitos subjetivos. Em síntese, os direitos fundamentais da primeira dimensão, de acordo com Cardoso (2010, p. 20), "foram o primeiro passo para a noção de dignidade humana que se tem hoje, pois libertaram o indivíduo da condição de súdito, para atribui-Ihe a condição de cidadão com direitos salvaguardados pelo Estado".

A respeito dos direitos fundamentais de segunda dimensão, estes se referem a prestações positivas do Estado, sendo direitos tidos de caráter social, cultural e econômico, bem como considerados direitos coletivos ou de coletividade. Estes referidos direitos tiveram como momento histórico e impulsionador os problemas sociais resultantes da Revolução Industrial europeia, a partir do século XIX (LENZA, 2012, p. 959).

Já os direitos de terceira dimensão ou direitos de solidariedade e fraternidade, é a consequência das reivindicações primordiais do ser humano, constituídas, principalmente, pelo processo provocado pelo segundo pós-guerra e seus violentos reflexos na qualidade de vida da pessoa humana. Além disso, tornou-se essencial a união de esforços do Estado e dos particulares para a construção de um ambiente mais justo e menos desigual, neste sentido, é a superação do público e do privado pelo reconhecimento dos interesses sociais (CARDOSO, 2010, p. 26). Ainda no tocante aos direitos de terceira dimensão, tem-se que:

\footnotetext{
Novos problemas e preocupações mundiais surgem, tais como a necessária noção de preservacionismo ambiental e as dificuldades para proteção dos consumidores [...]. 0 ser humano é inserido em uma coletividade e passa a ter direitos de solidariedade ou fraternidade.

Os direitos da 3. a dimensão são direitos transindividuais que transcendem os interesses do indivíduo e passam a se preocupar com a proteção do gênero humano, com altíssimo teor de humanismo e universalidade (LENZA, 2012, p. 960).
}

No que se refere à quarta dimensão, esta decorreu dos avanços no campo da engenharia genética, além de estar relacionada aos direitos à democracia, à informação e ao pluralismo (REIS; FONTANA, 2011, p. 121). Ou seja, tais direitos decorrem da globalização dos direitos fundamentais.

Sendo assim, analisando as dimensões, é notável a evolução conforme o desenvolvimento das afirmações dos direitos fundamentais. Da mesma forma, é possível perceber que o homem e sua dignidade estão, mesmo que implicitamente, presentes em todas as dimensões dos direitos fundamentais.

Ainda, a propagação dos princípios jurídicos, especialmente os que possuem natureza constitucional, ocasiona uma significativa discussão a respeito de sua aplicabilidade imediata. Tal debate movimentou a doutrina estrangeira, gerando repercussões no Brasil, principalmente entre os constitucionalistas, quando possuírem natureza de direitos fundamentais. Sendo assim, várias correntes se formaram a respeito do assunto. Para os civilistas brasileiros, não há dúvida da aplicabilidade imediata dos princípios constitucionais e direitos fundamentais, em razão, notadamente, da ocorrência de norma expressa na Constituição Federal de 1988, em seu artigo $5^{\circ}, \S 1^{\circ}$. A aplicabilidade imediata dos direitos fundamentais compreende não apenas as liberdades públicas em face do Estado, mas igualmente e especialmente as relações jurídicas estabelecidas entre os particulares, dado que a Constituição Federal não faz qualquer forma de restrição (LÔBO, 2006, p. 25-26).

Lenza (2012, p. 968) tem o mesmo entendimento a respeito da eficácia "irradiante" dos direitos fundamentais, concluindo que se fortalece a teoria da aplicação direta dos direitos fundamentais às relações privadas, a chamada teoria horizontal, notadamente perante atividades privadas que possuem um caráter tido como público, a título de exemplo, em matrículas de escolas, clubes associativos e em relações de trabalho.

Pode-se verificar, por fim, que a dignidade da pessoa humana surge para proteger o ser humano, mantendo e garantindo o viver com dignidade. Sendo assim, a dignidade da pessoa humana, presente em cada um dos direitos fundamentais, é o centro norteador da Constituição Federal de 1988, e sendo os princípios constitucionais 
e direitos fundamentais irradiados para todo ordenamento jurídico, serve de base também para o direito privado. Neste contexto, faz-se necessário analisar o princípio constitucional da solidariedade, o qual possui como pilar central a dignidade da pessoa humana.

\section{PRINCÍPIO CONSTITUCIONAL DA SOLIDARIEDADE E SUA APLICAÇÃO ENTRE} PARTICULARES

Após abordar a respeito da constitucionalização do direito privado e versar sobre a importância da dignidade da pessoa humana e dos direitos fundamentais no cenário da Constituição Federal de 1988, parte-se para o ponto central do artigo, qual seja, o princípio constitucional da solidariedade e sua aplicação entre particulares.

Inicialmente, convém mencionar que a ideia de solidariedade não se trata de algo novo, especialmente no pensamento ocidental, estando a sua origem vinculada a duas vertentes intelectuais, sendo elas o estoicismo e o cristianismo. Ademais, a solidariedade já era constatada também por meio dos discursos dos juristas romanos, visto que estes se utilizavam da palavra solidariedade para designar o laço que unia os devedores de uma dívida, cada um sendo responsável pelo todo (FARIAS, 1998, p. 188).

Contudo, apesar de verificar que a solidariedade não é uma novidade no mundo, a manifestação solidarista está especialmente relacionada à crise do modelo liberal a datar das transformações econômicas e sociais da metade do século XIX, que foi marcado pelo individualismo. Ou seja, neste contexto, o discurso de solidariedade representa uma crítica à democracia burguesa, considerando, portanto, uma nova forma de se pensar o direito, a sociedade e o próprio Estado (REIS; KONRAD, 2015, p. 77).

É possível igualmente notar que a concepção de solidariedade se tornou um anseio típico do século XX, quando o homem percebeu a possibilidade da destruição do planeta e do esgotamento dos recursos naturais. 0 sentimento de estarmos todos sujeitos a ameaças e crises globais nos fazem, indispensavelmente, solidários uns aos outros, gerando assim o dever de respeitar as futuras gerações. Da mesma forma, o referido século foi marcado pelas atrocidades cometidas no período da Segunda Guerra Mundial e como consequência de tais atos, observouse um novo modelo de relacionamento entre as pessoas, fundamentado na solidariedade social (MORAES, 2006).

Já a respeito da solidariedade no cenário nacional, tem-se que o Brasil, somente a datar da Constituição Federal de 1988, se preocupou em adotar tal valor como premissa maior, possuindo a partir de então uma base de valores e princípios de caráter democrático e visivelmente social. Isto posto, encontra-se no artigo $3^{\circ}$, inciso I, da Constituição Federal, o pressuposto de uma sociedade livre, justa e solidária, que tem por propósito fazer com que as individualidades se harmonizem com os interesses sociais da coletividade (CARDOSO, 2010, p. 3).

Apesar de a solidariedade estar expressamente prevista no inciso I do artigo $3^{\circ}$, salienta-se que todos os demais incisos do referido artigo da Carta Magna operam para se atingir, com efeito, uma sociedade livre, justa e solidária. Para tanto, requer-se uma atuação do Estado e da sociedade para promover o bem de todos. Ainda no tocante a Constituição Federal de 1988, pode-se dizer que:

[...] a própria Constituição Federal de 1988 é fruto de um movimento socializador e democrático e adota valores humanitários nas relações comunitárias para uma vida digna. Em seu art. $3^{\circ}$, I, é perceptível que as individualidades devem ser compatibilizadas com os interesses sociais da coletividade. Há, nesse sentido, uma maior preocupação com o "ser". Um direito sob a ética solidarista não se coaduna com a ideologia individualista, sendo a atual Constituição Federal uma desafiante do sistema e da estrutura do direito, uma vez que se atem a finalidades sociais específicas: construção de uma sociedade livre e justa; garantia do desenvolvimento nacional; erradicação da pobreza e da marginalização, reduzindo as desigualdades sociais e 
regionais; promoção do bem-estar de todos, sem preconceitos de origem, raça, sexo, cor, idade e qualquer outras formas de discriminação; uma ordem econômica fundada na valorização do trabalho humano e na livre iniciativa, cujo fim seja assegurar a todos uma existência digna, conforme os ditames da justiça social, nos termos do art. $3^{\circ}, 170$, CF (REIS; KONRAD, 2015, p. 81-82).

É possível igualmente, como já mencionado no item anterior, verificar expressamente a consagração da dignidade da pessoa humana na Constituição em vigor, em seu artigo $1^{\circ}$, inciso III. Constata-se assim que, atualmente, a dignidade da pessoa humana, juntamente com os direitos fundamentais, irradiam seus efeitos para todo o ordenamento jurídico. Neste contexto, de igual maneira, a dignidade da pessoa humana é o pilar central da solidariedade.

Imprescindível esclarecer que a solidariedade no contexto aqui tratado não significa "caridade", "filantropia" ou "empatia". A solidariedade, diferentemente dos outros termos mencionados, está ligada ao contexto de um princípio constitucional que serve como um veículo condutor da efetivação dos direitos fundamentais e da dignidade da pessoa humana.

0 princípio da solidariedade é um fato social, ao passo que não se pode imaginar o homem sozinho, tão somente pode-se cogitar o indivíduo como inserido na sociedade. A solidariedade, neste sentido, dá razão à existência do ser humano na sociedade, para que uma pessoa perceba na outra um valor, segundo Cardoso (2010, p. 91), "absoluto ainda mais amplo do que a justa conduta exigiria, e, ainda, como resultado de uma consciência moral e de boa-fé como comportamento pragmático para evitar lesão a outrem, a si mesmo e a sociedade".

A solidariedade busca responsabilizar não apenas o Estado, mas também, e especialmente, a sociedade nas relações interpessoais e as instituições particulares para conquistar uma realidade menos desigual e mais justa. Ainda, a solidariedade como princípio constitucional, de acordo com Cardoso (2010, p. 103), possui como propósito estabelecer que a sociedade se torne um ambiente favorável ao desenvolvimento da dignidade de cada pessoa de maneira integrada, em todas as suas dimensões.

No tocante a necessidade de superar a indiferença do homem em relação ao próprio homem, tem-se que, segundo Cardoso (2010, p. 111), “[...] todas as pessoas são em dignidade iguais, e por isso precisam encontrar na sociedade chances iguais para se desenvolverem. Para tanto, a abstração do interesse pessoal e a aplicação das justiças distributiva e social se faz necessário". Em um âmbito internacional, tem-se que a complexidade social, oriunda da globalização, fez reforçar a necessidade da solidariedade:

\footnotetext{
Expressão de igual dignidade entre os homens, a solidariedade atua como um freio à extensão da logica mercantil e a outras consequências advindas da globalização, entendendo-se que a organização da solidariedade é uma questão de futuro que se coloca em qualquer sociedade, A desigualdade, a fome e a discriminação engendradas pela globalização fazem ressurgir o sentimento de solidariedade na nação, motivo pelo qual o princípio da solidariedade deve impor-se, pois nenhuma ordem jurídica pode sobreviver sem ele (MELEU; BANDEIRA, 2017, p. 271).
}

Além disso, a solidariedade manifesta-se como o novo paradigma do direito privado, que como já mencionado e explorado no primeiro item da pesquisa, está fundamentado nos ideais de bem-estar, justiça social e que, após a constitucionalização do direito privado, possui a dignidade da pessoa humana como pilar central. Da mesma forma, o direito civil constitucional surge para proteger os mais fracos e vulneráveis, sendo um direito que reconhece o seu papel de conduzir com justiça e harmonia as relações interprivadas (CARD0SO, 2010, p. 170).

Assim, o discurso solidarista se propõe a formar um espaço social - o qual é constituído pelas relações existentes na teia da solidariedade social - que seja intermediário, com o intuito de eliminar as oposições tradicionais existentes entre o público e o privado, o Estado e a sociedade civil, o Estado e o mercado, por exemplo, 
estabelecendo uma nova forma e uma nova função simbólica de Estado que não seja regido pelo liberalismo, ou seja, que não seja classificado como Estado Liberal (FARIAS, 1998, p. 185).

Porém, existe a necessidade de enfatizar que a solidariedade aqui não se efetua apenas pelo Estado, de acordo com Farias (1998, p. 186) "supõe a existência de uma pluralidade de solidariedades realizadas em todo o espaço da sociedade civil, onde os grupos sociais são sujeitos de direitos no sentido de que são produtores de direitos autônomos em relação ao Estado".

Ainda, tem-se que o princípio da solidariedade no momento atual possui como finalidade estabelecer, conforme Reis e Lorenzi (2016, p. 46), "a democracia, humanizar as relações, conduzindo o indivíduo a refletir e efetivar a dignidade da pessoa humana. A partir desta perspectiva o princípio da solidariedade se faz presente nas relações interprivadas, historicamente individualistas, mas na modernidade solidarizaram suas instituições".

O princípio constitucional da solidariedade, resumido em simples palavras, responsabiliza tanto o Estado quanto os particulares nas relações interpessoais o dever de se colocar no lugar do outro, de forma a agir para que os direitos fundamentais e a dignidade da pessoa humana sejam efetivados, não sofrendo nenhuma espécie de violação. Ainda, cabe reforçar que a solidariedade é um fator e um dever jurídico.

Portanto, a partir da compreensão da solidariedade, surge uma nova realidade hermenêutica concentrada em uma sociedade livre, justa e solidária. Assim sendo, estando arrolada no artigo $3^{\circ}$, inciso I, da Constituição Federal de 1988, a solidariedade é um princípio constitucional que garante a efetividade dos direitos fundamentais e os concretiza. Logo, a solidariedade é um atual modelo das relações jurídicas, notadamente entre particulares e representa uma nova visão para o direito frente à concretização da dignidade da pessoa humana, atribuindo significado ao próximo e reconhecendo a existência do outro.

\section{CONSIDERAÇÕES FINAIS}

A partir das discussões que emergiram ao longo desta pesquisa, buscando verificar a efetividade da dignidade humana nas relações interpessoais pela vivência da solidariedade, chegou-se a algumas considerações. Sendo assim, quanto aos principais resultados, tem-se que não existe mais a grande dicotomia entre o direito público e o direito privado, característica que predominava no Estado Liberal, havendo atualmente uma intersecção jurídica entre eles.

Pode-se afirmar também que a constitucionalização do direito privado modificou o direito civil, passando este a ter como seu ponto central a pessoa humana e a sua dignidade. A respeito da dignidade da pessoa humana, apesar de constatar uma dificuldade em sua conceituação, tem-se que, em síntese, surge para proteger o ser humano, mantendo e garantindo o viver com dignidade. Já os direitos fundamentais positivados na Constituição em vigor, retratam a garantia de direitos alcançados no decorrer da evolução da sociedade, sendo essenciais para o constitucionalismo contemporâneo pelo o que simbolizam. Estando presente em cada um dos direitos fundamentais, a dignidade da pessoa humana é o centro norteador da Constituição Federal de 1988 e sendo os princípios constitucionais e direitos fundamentais irradiados para todo ordenamento jurídico, serve de base também para o direito privado.

Ainda, devido a Constituição Federal irradiar seus princípios constitucionais para todo o ordenamento jurídico, o princípio da solidariedade se encaixa neste contexto, atingindo o direito privado. Sendo assim, analisouse o princípio constitucional da solidariedade como um instrumento para concretizar os direitos fundamentais 
baseados na dignidade da pessoa humana. 0 princípio da solidariedade, assim como a dignidade da pessoa humana, norteia as ações do Estado e também dos cidadãos.

É possível, por fim, verificar a mudança da dinâmica das relações interpessoais, a partir do entendimento da importância do princípio constitucional da solidariedade e da sua vivência, garantindo o respeito à dignidade, assim como, o bem-estar comum, evitando a litigiosidade nestas relações. A exigência da solidariedade é fazer com que a sociedade se torne um ambiente adequado ao desenvolvimento da dignidade de cada pessoa de maneira integrada, em todas as suas dimensões. Ou seja, tem-se que o princípio constitucional da solidariedade ingressa no sistema jurídico como uma forma de atribuir significado ao próximo, em reconhecer a existência do outro, dando, assim, efetividade à dignidade da pessoa humana nas relações interprivadas.

\section{REFERÊNCIAS}

AWAD, Fahd. 0 princípio constitucional da dignidade da pessoa humana. In: Revista Justiça do Direito, 2006. Disponível em: <http://seer.upf.br/index.php/rjd/article/view/2182>. Acesso em: 11 set. 2018.

BARROSO, Luís Roberto. Curso de direito constitucional contemporâneo: os conceitos fundamentais e a construção do novo modelo. São Paulo: Saraiva, 2011.

BRASIL. Constituição (1988). Constituição da República Federativa do Brasil. Diário Oficial [da] República Federativa do Brasil, Brasília, DF, 5 out. 1988. Disponível em:

<http://www.planalto.gov.br/ccivil_03/constituicao/constituicaocompilado.htm>. Acesso em: 01 set. 2018.

CARDOSO, Alenilton da Silva. Princípio da solidariedade: o paradigma ético do direito contemporâneo. São Paulo: Editora Juarez de Oliveira, 2010.

FARIAS, José Fernando de Castro. A origem do direito de solidariedade. Rio de Janeiro: Renovar, 1998.

FINGER, Julio Cesar. Constituição e direito privado: algumas notas sobre a chamada constitucionalização do direito civil. In: SARLET, Ingo Wolfgang (Org.). A Constituição concretizada: construindo pontes com o público e o privado. Porto Alegre: Livraria do Advogado, 2000.

LENZA, Pedro. Direito constitucional esquematizado. São Paulo: Saraiva, 2012.

LÔBO, Paulo. A constitucionalização do direito civil brasileiro. In: Congresso internacional de direito civil constitucional, 2008, Rio de Janeiro. Direito civil contemporâneo: anais do Congresso Internacional de Direito Civil Constitucional da Cidade do Rio de Janeiro. São Paulo: Atlas, 2006. v. 1. p. 18-28.

MELEU, M. da S; BANDEIRA, L. C. A solidariedade como base para efetivação dos direitos humanos no âmbito internacional. In: Revista do Direito UFMS, Mato Grosso do Sul, v.3. n. 1. p. 259-274, 2017. Disponível em: <http://seer.ufms.br/index.php/revdir/article/view/4074/3303>. Acesso em: 26 set. 2018.

MORAES, Maria Celina Bodin de. 0 princípio da solidariedade. In: PEIXINHO; M. M.; GUERRA, I. F.; FILHO, F. N. (Orgs.). Os princípios da Constituição de 1988. Rio de Janeiro: Editora Lumen Juris, 2006.

NETO, Eugênio Facchini Neto. Reflexões histórico-evolutivas sobre a constitucionalização do direito privado. In: SARLET, Ingo Wolfgang (Org.). Constituição, direitos fundamentais e direito privado. Porto Alegre: Livraria do advogado, 2010.

REIS, Jorge Renato dos. A constitucionalização do direito privado: algumas considerações para análise. In: Revista Atos e Fatos, v. 1, p. 126-139, 2009.

; FONTANA, E. Direitos fundamentais sociais e a solidariedade: notas introdutórias. In: REIS, J. R. dos; LEAL, R. G. (Orgs.). Direitos sociais e políticas públicas: desafios contemporâneos. Santa Cruz do Sul: EDUNISC, 2011. 
.; KONRAD, L. R. 0 direito fundamental à solidariedade: a aplicação do instituto no direito civil. In: Revista novos estudos jurídicos, Itajaí, vol. 20. n. 1. p. 59-87, 2015.

; LORENZI, C. L. C. 0 princípio da solidariedade no negócio jurídico no sistema jurídico pátrio. In: GORCZEVSKI, Clóvis (Org.). Direito (Re)Discutido. 1 ed. Curitiba PR: Multidea, 2016

RICHTER, D.; TABARELLI, L. A efetivação dos direitos sociais como pressuposto à concretização da dignidade da pessoa humana e a jurisdição constitucional. In: GORCZEVSKI, C.; REIS, J. R. dos. (Orgs.) Direitos fundamentais sociais como paradigmas de uma sociedade fraterna: constitucionalismo contemporâneo. Santa Cruz do Sul: Editora IPR, 2008.

SARLET, Ingo Wolfgang. Dignidade da pessoa humana e direitos fundamentais na Constituição Federal de 1988. Porto Alegre: Livraria do Advogado, 2001.

Dignidade da pessoa humana e direitos fundamentais na Constituição Federal de 1988. Porto Alegre: Livraria do Advogado, 2011. 